\title{
Investments in the EU Power System: A Stress Test Analysis on the Effectiveness of Decarbonisation Policies
}

\author{
Pedro Crespo del Granado, Christian Skar, Haris Doukas, \\ and Georgios P. Trachanas
}

\begin{abstract}
Ambitious emission reduction targets are challenging the status quo on designing effective strategies for electricity generation portfolios. In this chapter, we consider the role of low-carbon technologies and determine the cost-benefits of policy strategies to mitigate greenhouse gas emissions in the EU. In particular, we look into how long-term scenarios for transmission expansion and decarbonisation policies influence the evolution of the EU power system infrastructure. We use an EU electricity investment model to determine the optimal portfolio of electricity generation technologies and compute their respective costs and emissions achieved towards 2050. Based on the investment model's results (strategies and suggested portfolios), we investigate how these portfolios perform under divergent policy or geopolitical developments. For this purpose, we apply a robust optimisation tool based on the min-max and the min-max regret criteria, which selects ideal portfolios by stress testing a particular scenario or policy choice under uncertainty of input parameters.

Results show that pursuing a strong transmission expansion strategy under the EU PRIMES reference case leads to the maximum regret, while relying on EU scenarios with strong prospects for decarbonisation, either with possibilities or with limitation on transmission expansion, leads to portfolios that exhibit the least variance. However, applying regret analysis on investment costs and total emissions indicates a limited transmission investment case as the more robust one, also noting that a high carbon price will accelerate the energy transition.
\end{abstract}

Keywords Investments - Decarbonisation - Robustness - Optimisation · Strategies · Energy transition

\footnotetext{
P. Crespo del Granado $(\varangle) \cdot$ C. Skar

Department of Industrial Economics and Technology Management, Norwegian University of Science and Technology (NTNU), Trondheim, Norway

e-mail: pedro@ntnu.no; christian.skar@ntnu.no

H. Doukas · G. P. Trachanas

Decision Support Systems Laboratory, School of Electrical and Computer Engineering,

National Technical University of Athens, Athens, Greece

e-mail: h_doukas@epu.ntua.gr; gtrachanas@epu.ntua.gr
} 


\section{Introduction}

Population growth and economic development constitute the primary factors of the increase in global carbon emissions (Raupach et al. 2007) in the last decades. Anthropogenic greenhouse gas (GHG) emissions have contributed to the increase in annual average global temperature. According to the Intergovernmental Panel on Climate Change, the range of climate change projections for global warming from 1900 to 2100 is from $1.4{ }^{\circ} \mathrm{C}$ to $5.8{ }^{\circ} \mathrm{C}$ (IPCC 2014). In order to limit GHG emissions, the electricity sector is facing the challenge to undertake a major transformational phase towards a low-carbon system by substituting the existing carbon-intensive technologies with climate-friendly ones. In this regard, energy analysts and policymakers face a future that is technologically, institutionally and politically complex and uncertain (Nikas et al. 2017); furthermore, assessments of the energy transition must take into account different perspectives to reflect the interests of numerous stakeholder groups (Papapostolou et al. 2017). On this matter, portfoliobased approaches are one of the established methods to evaluate national energy strategies and climate policies. They provide an analytical basis to devise generation mixes that take into account security of supply, climate targets, technological progression and costs.

Standard portfolio-based techniques usually provide an optimisation-based model to determine the mix of power generation technologies. To name but a few, McLoughlin and Bazilian (2006) apply a mean-variance portfolio (MVP) optimisation to analyse the Irish electricity generation mix. A similar approach is developed in White (2007) for California's electric utility resource planning, recommending an optimal generating portfolio for the inclusion of greater shares of renewable technologies. Awerbuch and Berger (2003) apply MVP analysis for the European Union by reflecting the risk of fuel, operation and maintenance, and construction period costs. By applying portfolio theory, Zhu and Fan (2010) evaluate China's 2020 midterm plans for generating technologies, while reflecting the risk of relevant generating cost streams and including $\mathrm{CO}_{2}$ emission scenarios. Also, Fuss et al. (2012) derive portfolios across various socio-economic scenarios for a range of stabilisation targets by including alternative risk measures.

All in all, uncertainty in portfolio optimisation techniques might be considered in the form of risk. However, another form of uncertainty in the model are its inputs and assumptions, which typically induces the formulation of different cases and scenario analyses. These scenarios are strongly related to different socio-economic, supply and/or stabilisation targets and assumptions. To cope with this kind of uncertainty, it is imperative to stress test the obtained solutions across different scenarios. In this direction, various robust decision support tools have been developed to provide solutions that perform well, independently of any scenario's realisation. The present study applies the min-max and the min-max regret criteria, ${ }^{1}$ both lying in the core of

\footnotetext{
${ }^{1}$ The robust decision under min-max criterion is that for which the lowest (highest) level of benefit (cost) taken across all possible input scenarios is as high (low) as possible. Regret is defined as the difference between the resulting benefit (cost) and the benefit (cost) from the decisions that would
} 
the so-called robustness analysis, to examine the performance of optimal technology portfolios by considering energy transition scenarios of the power system. The main goal is to identify a solution that performs well against the worst and/or the best case performance. Pure min-max criterion is appropriate for conservative decision makers, since it is associated with the worst-case scenario. Since hedging against uncertainty within energy planning is complex and fraught with multiple forms of uncertainties, robustness approaches have received increasing attention over the last years. For instance, in power systems planning, the uncertainties across the processes of transmission, conversion or distribution are treated with the adoption of interval programming in conjunction with regret analysis (see Dong et al. 2011 and the references therein). Furthermore, we refer to van der Weijde and Hobbs (2012) and Munoz et al. $(2014,2017)$ concerning transmission planning, and to Fan et al. (2010) and Morris et al. (2018) regarding investment decisions under policy uncertainty, and risk aversion and $\mathrm{CO}_{2}$ regulatory uncertainty in generation investments, respectively.

In this chapter, to analyse the decarbonisation of the EU power system, we apply a stochastic power investment model to determine the optimal technology portfolios under certain scenarios. Namely, we use the EMPIRE (European Model for Power System Investment with Renewable Energy) model, developed by Skar et al. (2016a, b). EMPIRE, formulated as a multi-horizon stochastic programme, incorporates long- and short-term system dynamics while optimising investments under operational uncertainty. It is well known that the consideration of renewable technology in the generation mix, in particular wind and solar power, impacts the supply and demand balance, due to the intermittent and uncontrollable nature of these technologies. EMPIRE is designed to handle these challenges. In contrast to other power sector models, the major contribution of EMPIRE is that it simultaneously incorporates short- and long-term dynamics, in conjunction with short-term uncertainty. Dynamics refer to multiple investment periods coexisting with multiple sequential operational decision periods, while uncertainty is enhanced through multiple input scenarios that describe operating conditions. That is, EMPIRE is a capacity and transmission expansion model, designed to determine optimal capacity investments and system operation over long-term planning horizons, extended in a 40-50-year basis. A central planner's perspective is adopted, minimising a system's cost while serving a price inelastic demand. Regarding the effect of short-term uncertainty on investment decisions, the methodology used is based on the principles of multihorizon stochastic programming, as proposed by Kaut et al. (2014). Related expansion models in the literature are, for example, the DIMENSION (Richter 2011) model used by Jägemann et al. (2013), who analyse the costs for the decarbonisation of the European power sector. Similarly, another dynamic investment model, the LIMES-EU+, was adopted by Haller et al. (2012), where carbon capture and storage

have been taken knowing prior to the decision time which particular input scenario would occur. Applying the min-max criterion to the regret values, we obtain the robust min-max regret decisions (Kouvelis and Yu 1997). 
(CCS) and nuclear power are excluded. Both optimisation models are deterministic, in contrast to EMPIRE's stochastic features. In the multi-stage stochastic model E2M2 (Swider and Weber 2007), short-term wind uncertainty is analysed for the German power system. Another similar model is the two-stage stochastic model TIMES (Seljom and Tomasgard 2015), which also includes short-term uncertainty.

In our stress testing framework assessment, EMPIRE determines the optimal portfolio of electricity generation technologies and calculates their respective costs and emissions achieved for the 2015-2050 period. Each long-term strategy obtained by EMPIRE assumes the realisation (model inputs) of a future technological progression or geopolitical scenario assumptions. For instance, technology evolution differentiation represents the variability of the scenarios. To hedge against the possible realisation of certain technological or geopolitical scenarios, we apply robust optimisation through the min-max and min-max regret criteria. In the first case, a safe performance is guaranteed, independently of any selection within the input parameter dataset. In the regret analysis case, the stress test of input data means that the decision maker measures the deviation from optimality as long as input varies within the scenario set, and then the min-max criterion is applied to guarantee a safe "distance" from that optimality.

We chose to implement robust optimisation, since we refer to risk-averse decision makers, either concerning the best or the worst case. The literature with applications of min-max regret analysis in the energy sector is quite extensive. For example, in Dong et al. (2011), min-max regret analysis is incorporated in combination with interval linear programming for the study of power management systems under multiple supply and demand scenarios. In Li et al. (2016), electrical power generation planning is studied while considering discrete scenarios of possible climate change outcomes. In Kazakci et al. (2007), energy crop supply is measured through a linear mathematical programme. In the framework of climate change mitigation policy, we refer to Loulou and Kanudia (1999), where a min-max regret formulation is proposed to determine strategies for GHG emission reduction. In Li et al. (2011), an interval model is developed to support planning of GHG mitigation within an uncertain energy system. In addition, these approaches are also applied to solid waste management by combining tools for interval and robust optimisation ( $\mathrm{Li}$ and Huang 2006; Chang and Davila 2007). However, we should mention that minimising maximum cost or regret is a rather extreme form of risk aversion and that there exist other alternatives to model it, such as using utility functions (preferred by economists) or Conditional Value at Risk (preferred by engineers). To summarise, the objective of this study is to (1) analyse the robustness of different pathways for the energy transition of the power sector by stress testing their outcomes across individual scenarios and (2) propose a multidisciplinary method to complement a power system capacity expansion model with a robustness-based approach (min-max regret analysis).

The next section presents the main features of the EMPIRE model. This is followed by Sect. 3, which describes the implementation of four distinct cases and their respective results. Then, Sect. 4 presents the two robustness tools that apply the stress test analysis on optimal investment portfolios across the different cases. 


\section{Modelling Investments in Electricity Generation and Transmission}

\subsection{Short-Term vs. Long-Term Considerations for Optimal Portfolio}

There is a multitude of energy models looking at different dimensions of the power system. Main difference among models is the level of technical detail, representation of uncertainty (e.g. RES or demand variations), temporal considerations, spatial aggregation and planning horizons (for a review, see Crespo del Granado et al. 2018). Typically, the fundamental problem is to decide the short-term scheduling of power plants (e.g. coal, gas, hydro or nuclear) based on generation costs, plants' operational limitations and RES-load interactions. This model, in the literature, is known as the "unit commitment problem", the "optimal economic dispatch" or simply the generation dispatch. To decide the power dispatching of a determined number of coal or gas power plants, nuclear reactors or oil generators, the model determines an optimal supply portfolio based on functions representing economic decisions and energy generation physics. While this kind of model represents the supply-demand balance in detail with a high time resolution (hourly decisions), it usually does not consider long-term decisions for capacity planning. In contrast, models for long-term capacity planning leave behind detail engineering aspects of operations. Raising a causality dilemma since the short-term decisions require an adequate generation capacity to satisfy demand, while long-term investment decisions are a consequence on how much adequacy is required in the short term. As both planning horizons are nonmutually exclusive (see Fig. 1), investment models have come up with different assumptions to represent operational decisions and features of the power system. For the EMPIRE model, these assumptions are as follows:

- Operations and investment horizon: As hourly operations in 1 year compromise 8760 periods, repeating them for multiple years increases the dimensionality of the problem. Long-term planning problems typically analysed years to decades ahead and simulating short-term problems for large time spans might create an intractable problem. A common approach is to sample representative weeks. In EMPIRE, we sample typical weeks per season along with 2 weeks representing extreme cases (e.g. high peak demand and low RES availability). These weeks' parameters are updated for incoming investment periods. EMPIRE considers a planning horizon from 2015 to 2050 . Investment windows are every 5 years in which the representative operational weeks are scaled up to resemble the 5 years in operation. That is, all investment periods are in a single optimisation along with operation snapshots (see similar approach in Haller et al. 2012).

- Spatial aggregations: EMPIRE model covers the European Economic Area countries (see Fig. 2, 31 European countries along with 55 interconnectors). EMPIRE models each country as a single node together with existing capacity 


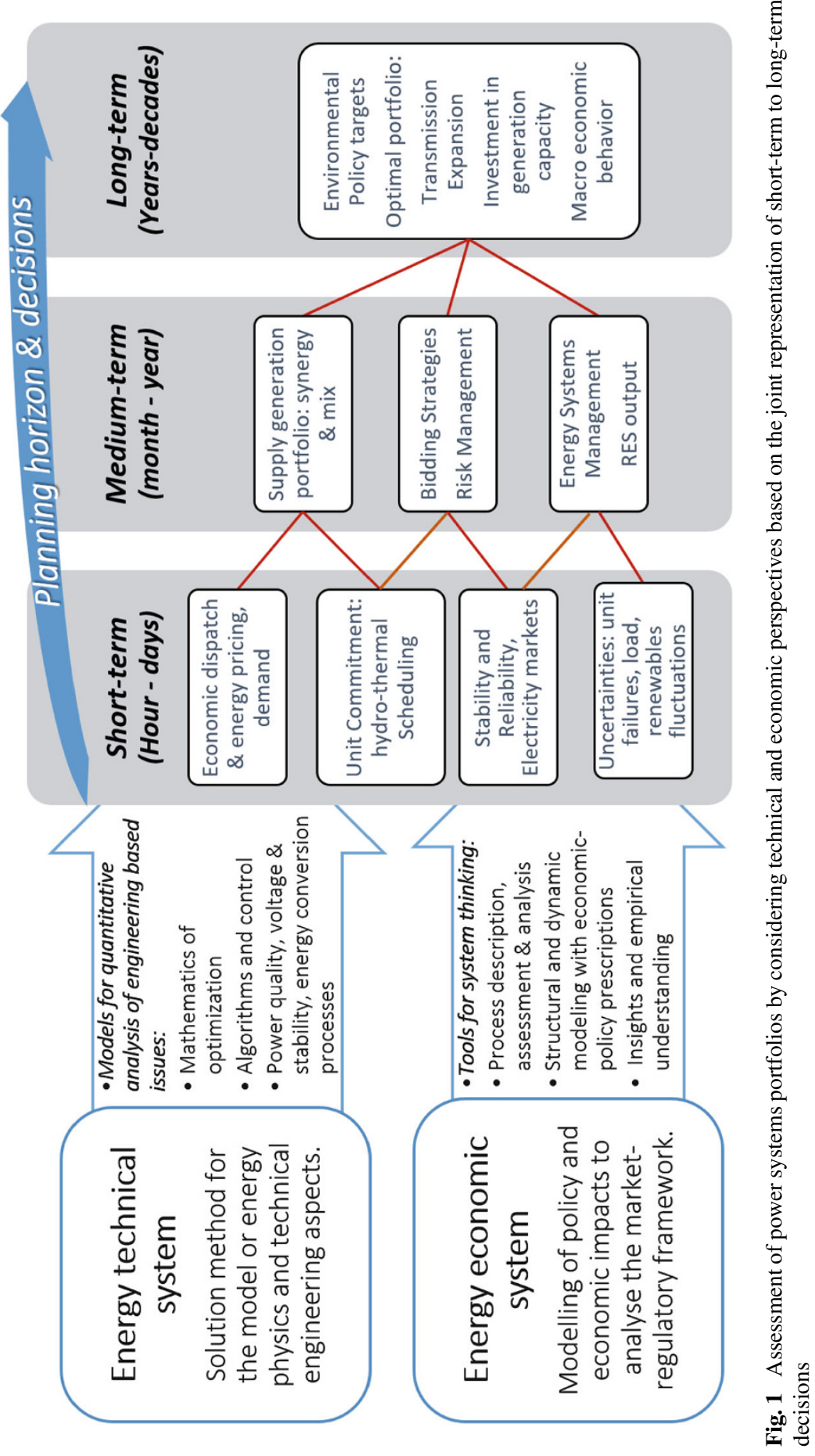



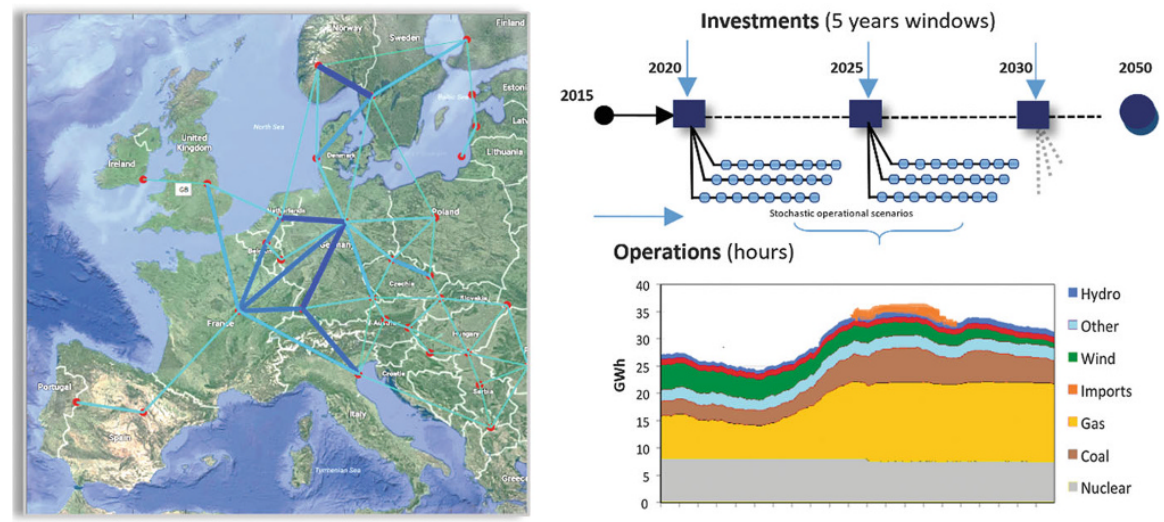

Fig. 2 EMPIRE model EU spatial coverage combining short (operations)- and long-term (investments) decisions to determine optimal portfolios for the power system

and estimated demand. The net transmission capacity defines the country connection capacity to neighbouring regions. That is, the interconnection among nodes in the model resembles a transportation problem.

- Technical engineering aspects: EMPIRE short-term operational aspects represent hourly decisions of the generators and transmission exchange between countries. Generators are aggregated by type, for example, nuclear generators have a single variable per country. As an energy system model, EMPIRE does not consider power flows and voltage relationships. As the main interest is the long-term expansion of the system, the model also assumes linear production cost profiles for all generators.

- Policy and economic perspectives: EMPIRE can set RES targets and calculates $\mathrm{CO}_{2}$ emissions per country. Main model outputs are the usage factor of power plants, load shedding, RES curtailments, transmission infrastructure investments and cooperation among countries to meet policy objectives. Hence various policies can be tested by changing the model parameters (technology costs, demand or RES targets), including the prospects of development of technologies (e.g. CCS) and considering assumptions on transmission expansion possibilities.

In summary, EMPIRE intends to combine as much as it can from both worlds: short-term (operational) and long-term (strategic) decisions. In addition, the model provides enough rich technological details to provide rational insights for the longterm planning of the power system. Figure 1 epitomises this discussion in which the modelling approach might take a technical engineering perspective or an economic viewpoint mainly focuses on the empirical understandings of impacts in policymaking. The EMPIRE model intends to encompass a compromise of this vision since its formulation convenes as much as it can from different perspectives. For a further discussion on tools for integrated assessments, combining models and strength-weaknesses of different modelling approaches, refer to Crespo del Granado et al. (2018). 


\subsection{EMPIRE Model Formulation}

Modelling a portfolio of energy units, as an hourly coordinated supply-demand system, is typically formulated as a multiperiod optimisation model. This takes into consideration the cost of running the generation units, ramp-up time and the unit input-output capacity (power rates). As a result, the optimisation model objective is to minimise the investment and operational costs. The main decision variables are the investment decisions and which generation units to use and when: peak time, base load, smoothing renewables and the usage of transmission capacity. EMPIRE perspective is an economic social surplus maximisation that assumes perfectly competitive markets under predetermined consumer decisions. As noted earlier, a central feature in EMPIRE is the representation of two timescales, the long term (strategic) and the short term (operational). Operational decisions are associated with a strategic stage in order to co-optimise long-term investment decisions and the short-term operational decisions. That is, strategic decisions face supply-demand balancing decisions under uncertainty. For example, in Fig. 2, observe the structure of the 5-year investment windows subjected to operational uncertainty. Investment variables (generation and transmission expansion) in 2020 have specific hourly load profiles per country and must determine the operations of the units and hence decide the optimal portfolio from 2025 onwards. The model includes a discount rate to calculate the net present value (NPV) of investments. This structure follows a multihorizon stochastic framework in which the operational uncertainty is in the load profiles and wind and solar power generation. For a more comprehensive discussion on setting up the EMPIRE model, refer to Skar et al. (2016a, b).

\section{EMPIRE Objective Function}

As aforementioned, to take into account long-term and short-term decisions, EMPIRE minimises the NPV of investments based on operational decisions. On one hand, the objective function contains the investment decisions for generation $\left(x_{g i}^{\text {gen }}\right.$, capacity investment in generator $g$ at year $\left.i\right)$ and transmission $\left(x_{l j}^{\text {tran }}\right.$, investing in transmission line $l$ at year $i$ ) under $\operatorname{costs} c_{g i}^{\text {gen }}$ and $c_{l i}^{\text {tran }}$, respectively. On the other hand, the presentation of the operation decisions comes from the production of generator $g$ and $y_{\text {ghi }}^{\text {gen }}$ for operational hour $h$ in year $i$ under stochastic scenario $\omega$. In addition, the operations consider load shedding $\left(y_{n h i \omega}^{\mathrm{LL}}\right)$ at node $n$ (country), under operational hour $h$ in year $i$ and stochastic scenario $\omega$. Both $y_{\text {ghi }}^{\text {gen }}$ and $y_{\text {nhi }}^{\mathrm{LL}}$ face costs of producing electricity $\left(q_{g i}^{\mathrm{gen}}\right)$ and the cost of using load shedding $\left(q_{n i}^{\mathrm{VoLL}}\right)$. In short, EMPIRE objective function is as follows:

$$
\begin{aligned}
\min _{\mathbf{x}, \mathbf{y}} z= & \sum_{i \in \mathcal{I}} \delta_{i} \times\left\{\sum_{g \in \mathcal{G}} c_{g i}^{\text {gen }} x_{g i}^{\text {gen }}+\sum_{l \in \mathcal{L}} c_{l i}^{\mathrm{tran}} x_{l i}^{\mathrm{tran}}+\sum_{\omega \in \Omega} p_{\omega} \times \sum_{h \in \mathcal{H}} \alpha_{h}\right. \\
& \left.\times \sum_{n \in \mathcal{N}}\left(\sum_{g \in \mathcal{G}_{n}}\left[q_{g i}^{\text {gen }} y_{\text {ghi }}^{\text {gen }}\right]+q_{n i}^{\mathrm{VoLL}} y_{\text {nhi }}^{\mathrm{LL}}\right)\right\}
\end{aligned}
$$


To compute the NPV in Eq. (1), we set a discount factor $\delta_{i}$ per year $i$. For the operations, we apply a factor $\alpha_{h}$ to scale up and match the total number of hours of the investment period. Recall that the time span of the investments is 5 years for which we use representative weeks of the year and hence the scale up factor accounts for the remaining hours. Note that since we consider stochastic scenarios for renewables and demand, we assign the respective probabilities $p_{\omega}$ for operations of that scenario.

\section{EMPIRE Constraints}

Since it would be unrealistic to invest in certain generators for certain countries (e.g. wind offshore for Switzerland) or allow sudden large investments on each period, Eq. (1) is subjected to investment constraints (period-wise and cumulative), that is, a restriction by an upper bound $\left(\bar{x}_{t n^{*}}^{\text {gen }}\right)$ on investments in new capacity for generator $g$ along with the cumulative installed generation over the planning horizon. This also considers the retirement of power plants based on the retired share $\left(\rho_{g i}\right)$ of generator $g$ 's initial capacity by year $i$. These constraints are

$$
\begin{aligned}
& \sum_{g \in \mathcal{G}_{n t}} x_{g j}^{\text {gen }} \leq \bar{x}_{n t i}^{\text {gen, Period }}, \quad n \in \mathcal{N}, t \in \mathcal{T}, i \in \mathcal{I} . \\
& \sum_{j=1}^{i} \sum_{g \in \mathcal{G}_{n t}} x_{g j}^{\text {gen }} \leq \bar{x}_{n t}^{\text {gen, Cumulative }}-\left(1-\rho_{g i}\right) \bar{x}_{g 0}^{\text {gen }}, \quad n \in \mathcal{N}, t \in \mathcal{T}, i \in \mathcal{I} .
\end{aligned}
$$

Likewise, investment constraints for transmission (exchange) capacity are also set up:

$$
x_{l i}^{\text {tran }} \leq \bar{x}_{l i}^{\text {tran,Period }}, \quad l \in \mathcal{L}, i \in \mathcal{I}
$$

As for the equations to represent the operations, these are based on the usage of generators $g$ at node $n$, the interaction (flow) with neighbouring nodes, the capacity and usage characteristics of the generators, hydro or alike storage technologies and the emission standards per country. The details of these operational constraints are as follows:

1. Supply-demand balance (production + losses*import-exports-pumping + load shedding $=$ load)

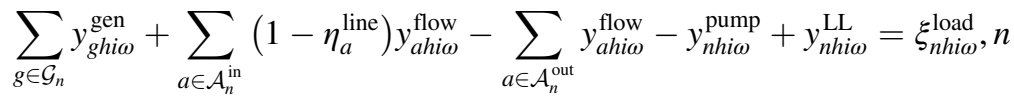

$$
\begin{aligned}
& \in \mathcal{N}, h \in \mathcal{H}, \omega \in \Omega, i \in \mathcal{I} .
\end{aligned}
$$

2. Generation capacity constraint based on existing a prior capacity plus the invested capacity for year $i$ under 


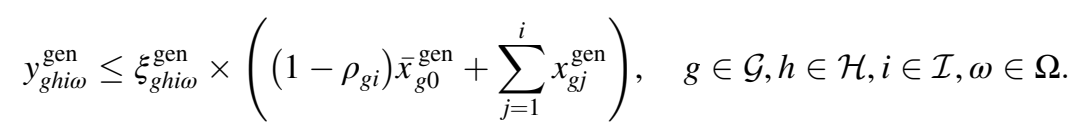

3. Upward ramping constraints to simulate appropriate load following of the generators:

$$
\begin{aligned}
& y_{\text {ghi } \omega}^{\text {gen }}-y_{g(h-1) i \omega}^{\text {gen }} \leq \gamma_{g}^{\text {gen }} \times\left(\left(1-\rho_{g i}\right) \bar{x}_{g 0}^{\text {gen }}+\sum_{j=1}^{i} x_{g j}^{\text {gen }}\right), \quad g \in \mathcal{G}^{\text {Thermal }}, \\
& s \in \mathcal{S}, h \in \mathcal{H}_{s}^{-}, i \in \mathcal{I}, \omega \in \Omega
\end{aligned}
$$

4. Flow constraint-limit flow on arcs (directional arcs and lines are symmetric). It also considers a prior line capacity plus the capacity expansion investment for year $i$ :

$$
y_{\text {ahi } \omega}^{\text {flow }} \leq \bar{x}_{l 0}^{\text {tran }}+\sum_{j=1}^{i} x_{l j}^{\text {tran }}, \quad l \in \mathcal{L}_{n}, a \in \mathcal{A}_{l}, h \in \mathcal{H}, i \in \mathcal{I}, \omega \in \Omega
$$

5. Hydro energy constraint - limit total hydropower production within a season (due to water availability)

$$
\sum_{h \in \mathcal{H}_{s}} y_{\text {ghi }}^{\text {gen }} \leq \xi_{\text {gsi }}^{\text {RegHydroLim }}, \quad g \in \mathcal{G}^{\text {RegHydro }}, s \in \mathcal{S}, i \in \mathcal{I}, \omega \in \Omega .
$$

6. Pump-storage upper reservoir capacity and inter-temporal balance for storage:

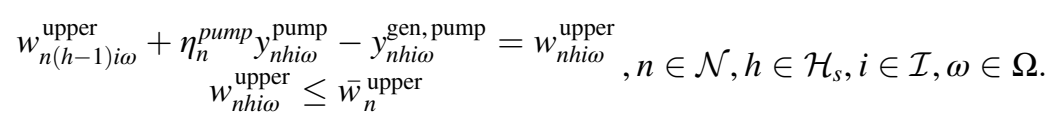

Appendix 1 notes the nomenclature description of the sets, parameters and variables used in the above formulation. Note that EMPIRE has been used in other studies which present a more comprehensive model formulation, data sources and other details (see, for example, Skar et al. (2014, 2016a, b) and ZEP (2013, 2014)). Note that exogenous drivers of investments in the EMPIRE model are changes in demand, retirement of the existing generation fleet, changes in fuel prices and a price of carbon. Technological advancement, such as investment cost reductions and efficiency improvements for thermal generation, plays an important role in the design of the optimal generation portfolio and is included in the model (see Appendix 2 for data inputs). EMPIRE computational dimension includes approximately 
15 million variables and 22 million constraints, and it takes from an hour to 5 hours to solve (depending on scenario, technology choice and solver configurations).

\section{Energy Transition: Cases and EMPIRE Model Results}

\subsection{Defining Cases}

The EU Energy Roadmap 2050 and various stakeholders' discussions with the European commission outlined four main decarbonisation routes for the energy sector; these are energy efficiency, RES, nuclear and CCS. These decarbonisation options have the premise that European integration will be one of the driving forces in its success. Cooperation among countries and political determination will generate measures for the integration of European electricity markets, viability of infrastructure projects of common interest (PCI), common climate targets (e.g. the Paris agreement) and joint policies to accommodate higher shares of RES in the system. The cooperation among different EU actors and countries towards 2050 is assumed to be one of the cornerstones of the energy transition. As a result, some scenariobuilding studies (Bauer et al. 2017) have discussed the degree of cooperation achievable in the long term as a measure to weigh-in and to formulate different scenarios towards 2050 .

In this spirit, to understand the consequences of assuming different evolutions of the generation portfolio of the electricity system, we define four cases ${ }^{2}$ that are in line with the scenarios developed by the PRIMES model (National Technical University of Athens 2010) for the EU Low Carbon Roadmap 2050 (European Commission 2011). That is, we use the following two EU scenarios:

- The "PRIMES Reference scenario" projects energy trends to 2050 based on policies already adopted by March 2010. It includes policies agreed in the EU climate and energy package of 2009.

- The "PRIMES Decarbonisation scenario". We use the EUCO 27 variant, which assumes international agreement on an effective global action plan complemented with policies for carbon pricing across all sectors. It positions the adoption of major low-carbon technologies in the energy sector, e.g. energy efficiency and RES, CCS, nuclear and electrification of transport.

Since the energy transition is affected by technological development, climate change commitments, energy security and international agreements, both PRIMES scenarios might evolve differently under different contexts. For example, if cooperation among nations does not occur as expected, this might limit the integration of EU electricity markets and the creation of PCI. We can reflect this hypothetical

\footnotetext{
${ }^{2}$ Note that we refer to cases as the instances in which we perform an analysis and model implementation, while scenarios are the input assumptions to the modelling exercise.
} 
situation by limiting the expansion of transmission capacity in EMPIRE. Limiting transmission expansion could reflect the view that EU nations find difficult to develop stronger cooperation. In short, this argument defines four cases:

- PRIMES reference case, transmission options available or optimised (OTR)

- PRIMES decarbonisation case, transmission options available or optimised (OTD)

- PRIMES reference case, transmission expansion limited (LTR)

- PRIMES decarbonisation case, transmission expansion limited (LTD)

The overall results illustrated in Fig. 3 show the developments of the energy mix for these four cases. For the years 2010 and 2015, historic data are used for all generation and transmission capacities; however, the economic dispatch comes from the model. The year 2020 is the first investment period for generation capacities. As for the transmission investment cases (LTR and LTP), this is set to the reference capacities in ENTSO-E's 10-year network development plan (TYNDP) 2016 (see ENTSO-E (2015) for more information). The major differences between the decarbonisation and the reference cases are as follows: The demand for electricity is higher, and the price of carbon is higher in the decarbonisation cases. The main effect on EMPIRE is that the need for investments is higher and that the generation mix is forced to be cleaner.

\subsection{Results for 2020-2030 Period: All Cases}

As expected, there are similarities in all scenarios in 2020 and 2030-regardless of input data used (reference or decarbonisation scenario) and whether transmission investments are restricted beyond 2020. This is because all the cases share similar features for these periods since transmission expansion is the same and difference between reference and decarbonisation is not significant for demand projections. The first effect that stands out is the expansion of the share of coal generation in 2020 for all scenarios. On one hand, this is because of the retirement of ageing nuclear power capacity with zero emission that is not replaced by new capacity. On the other hand, due to moderate carbon prices ( $15 \mathrm{EUR} / \mathrm{tCO}_{2}$ ) and a high price ratio of gas to coal (at about 3.4), new coal generation is the lowest cost option to replace the retired capacity. Hence, this new coal capacity takes over the share of the existing natural gas installed in the system, leading to a small increase in power sector emissions from 2015 which is not necessarily in line with the European Union's climate goals set for 2020 (a 20\% emission reduction compared to 1990s level). In reality the power sector emissions, subject to the EU Emissions Trading System, would not be allowed to increase, and the economic advantage of coal compared to lower emission technologies such as renewables, natural gas and nuclear would be counteracted by an increase in the ETS price. However, as the ETS price increases in the period beyond 2020, this becomes less of an issue as the emissions reduction from EMPIRE approach levels is in line with EU's climate policy. 
a) Results of investing in transmission and generation towards 2050

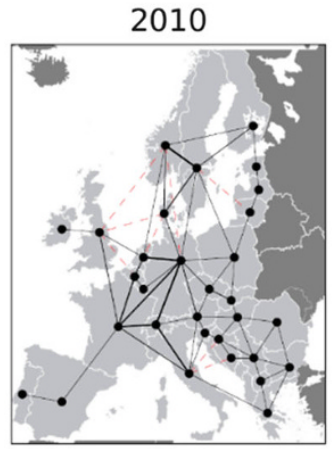

No invest

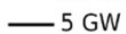

Reference 2050

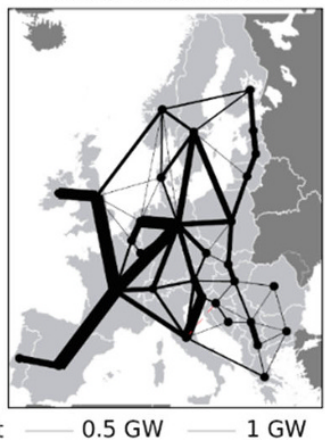

$10 \mathrm{GW}$
Decarbonization 2050

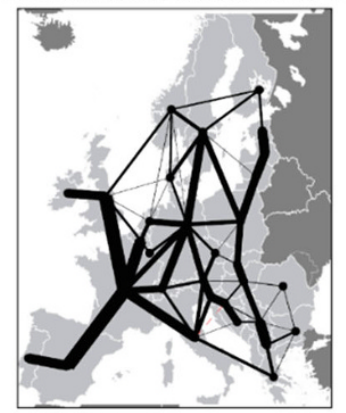

$2 \mathrm{GW}$
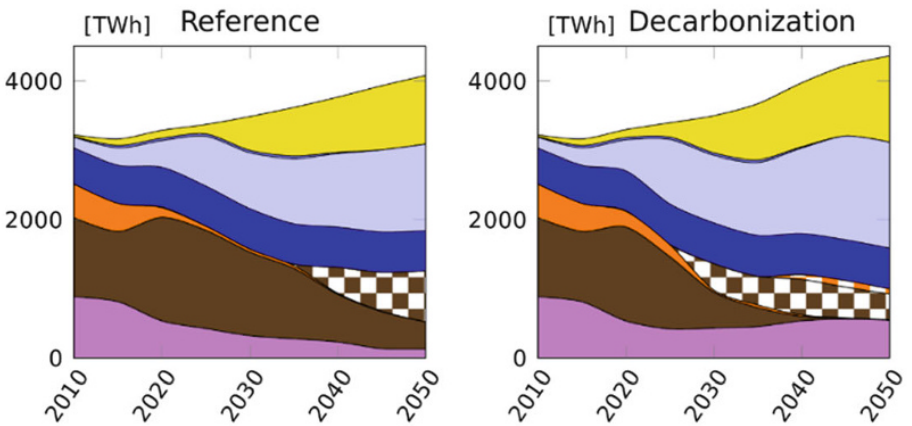

$\square$ Solar PV

$\square$ Wind Offshore

$\square$ Wind Onshore

Hydro/Geo,

$\square$ Bio

$\square$ Gas CCS

ECoal CCS

$\square$ Unabated Gas

$\square$ Unabated Coal

$\square$ Nuclear

$\nu^{2} \imath^{0} \imath^{0} \imath^{0}$

b) Investing in generation under restrictions for transmission
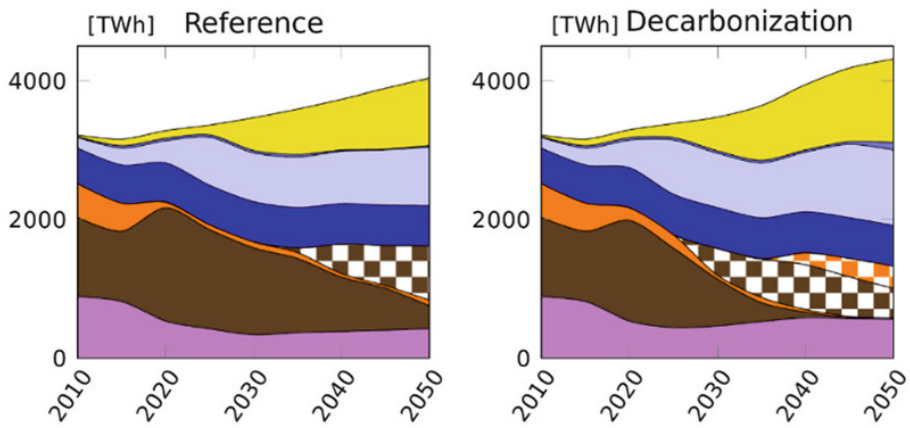

Fig. 3 Reference and decarbonisation cases under transmission capacity available (a) or restricted (b) 
As for renewables, most of the investments in the period until 2030 are in onshore wind power. Only moderate investments are in solar PV - of around $25 \mathrm{GW}$ for the reference cases and $75 \mathrm{GW}$ in the decarbonisation cases.

\subsection{Results for Reference Cases 2030-2050}

For the reference scenario cases, unabated coal generation remains the main fossil fuel technology in the generation mix until 2040, in both with and without transmission expansion cases. In 2040 coal with CCS is deployed achieving a high share of the generation mix than unabated coal towards 2050. For renewables, mainly onshore wind and solar PV, there is a massive deployment for both technologies in the 2030-2050 period. When allowing for transmission expansion, more than $50 \%$ of the electricity produced comes from these sources. One of the most significant effects of not expanding capacity in the transmission system is that less onshore wind generation is deployed. This shows that cost-optimal wind deployment relies heavily on the ability to effectively share wind resources using the grid.

In the case with limited transmission expansion, nuclear power sees reinvestments (at a cost of $4500 \mathrm{EUR} / \mathrm{kW}$ ), and this capacity is largely what is used to make up the reduction in wind generation compared to the alternative transmission case. As can be seen in the EU grid maps of Fig. 3a, there is a significant increase of capacity on the interconnectors between countries. For example, the cross-border connections between France, Germany, Spain, the UK and neighbouring countries are reinforced heavily.

\subsection{Results for Decarbonisation Cases 2030-2050}

The main differences between exogenous inputs between the decarbonisation case and the reference case are that the former has a steeper increase of the ETS price and a higher electricity demand. In comparison with the results of the reference cases, there are effects worth mentioning:

- Deployment of CCS occurs a full decade earlier in the decarbonisation cases than the reference cases, in 2030 rather than 2040.

- Nuclear power sees reinvestment in both decarbonisation cases.

- Solar and onshore wind expansion is more aggressive in these cases than the reference case, reaching a level of around $65 \%$ of the generation mix in the transmission expansion cases. By 2050 all unabated fossil generation has been completely phased out.

- As in the reference case, we observe that less wind onshore is installed when there are no investments in the transmission capacity beyond 2020. This is made up by fossil fuel with CCS, most notably gas CCS. But a small amount of offshore wind is deployed in the restricted transmission case. 
For the cases with investments in transmission capacity, the overall picture is alike to the reference case, although with a few distinctions. There are significant investments in Central Europe, but some connections see different investments in the decarbonisation case than the reference. For instance, the interconnector between France and Germany has less capacity in the decarbonisation case, whereas the links from France to Switzerland and Switzerland to Germany are reinforced. Another notable difference is the increased investments from the Baltic countries in the north to the Balkans in the south in the decarbonisation case. This is a result of the increased penetration of variable renewable resources in the decarbonisation case, which has a strong effect on the optimal design of the transmission system for balancing supply and demand throughout the continent.

\section{Robustness Tool and Stress Testing the Optimal Portfolios}

In this section, we present the mathematical formulation and the structure of the min-max and min-max regret criteria. Uncertainty is represented deterministically through the concept of scenario (see also Kouvelis and Yu 1997). Potential future realisation of the model is represented through a particular scenario, which occurs with a positive but unknown probability.

Our aim is to identify robust strategies corresponding to a plausible objective performance, along all scenarios of our decision model. First, we apply the min-max criterion, pointing out that the robust decision is that having the best worst-case performance across all future scenarios. Let us explain this in the discrete scenario case.

Consider the following optimisation problem:

$$
\min _{x \in X} f(c, x)
$$

where $x=\left(x_{1}, \ldots, x_{N}\right) \in X \subseteq \mathbb{R}^{N}$ and $c=\left(c_{1}, \ldots, c_{N}\right) \in \mathbb{R}^{N}$. The feasible set $X$ contains the admissible decision variables $\left(x_{1}, \ldots, x_{N}\right)$ satisfying some prespecified constraints of the model. The input parameters $\left(c_{1}, \ldots, c_{N}\right)$, inserted exogenously, define the uncertainty of the model in the following sense: if $S=\left\{s_{1}, \ldots, s_{p}\right\}$ denotes the finite set of all potentially realisable input data scenarios, then realisation of a certain scenario $s \in S$ means that

$$
c=c^{s}=\left(c_{1}^{s}, \ldots, c_{N}^{s}\right)
$$

While $S$ is not identically a singleton, uncertainty is then inherent. Let $X$ and $S$ be the feasible set and the discrete scenario set, respectively, for the minimisation problem (10). The corresponding min-max decision is exactly

$$
x_{\text {minimax }}=\arg \min _{x \in X} \max _{s \epsilon S} f\left(c^{s}, x\right) .
$$


Subsequently, consider the optimal solution for scenario's $s \in S$ realisation, which is

$$
x_{s}^{o p t}=\arg \min _{x \in X} f\left(c^{s}, x\right),
$$

and the corresponding optimal performance:

$$
f_{s}^{o p t}:=f\left(c^{s}, x_{s}^{o p t}\right)
$$

Given an admissible decision $x \in X$, its regret $R(x, s)$, under scenario's $s \in S$ realisation, is defined as its deviation from scenario's $s \in S$ optimal performance, that is,

$$
R(x, s):=\left|f\left(c^{s}, x\right)-f_{s}^{o p t}\right|
$$

For any decision, we are interested in identifying the worst deviation from optimality across the whole range of uncertainty. Therefore, it is reasonable to obtain information on the worst regret. For any decision $x \in X$, its maximum regret is defined as

$$
R_{\max }:=\max _{s \in S} R(x, s)
$$

Then, the min-max regret criterion aims at identifying the solution presenting the best worst-case deviation from optimality, independently of the input data realisation. The corresponding min-max regret decision is exactly

$$
x_{\text {regret }}=\arg \min _{x \in X} \max _{s \in S} R_{\text {max }}=\arg \min _{x \in X} \max _{s \in S}\left|f\left(c^{s}, x\right)-f_{s}^{\text {opt }}\right| .
$$

Subsequently, we carry out a stress testing for the investments in electricity generation and transmission with respect to their performance across different scenarios. More precisely, we measure the variation of the cumulative 2010-2050 investment costs and cumulative 2010-2050 emissions across different scenarios on transmission and decarbonisation. Regarding scenarios, we apply the four cases previously described: the two PRIMES scenarios (reference and decarbonisation) with assumptions on transmission expansion (either optimised investments or limited to just the 10-year development plan by ENTSO-E).

First, we consider the objective referring to the cumulative 2010-2050 costs in billion $€(2010)$ as they are presented in Table 1 . In the first column, we consider the optimal portfolio investments per scenario, and we examine their performance across the remaining investment scenarios. Then, we carry out min-max and min-max regret analysis to obtain the most robust state. According to the min-max criterion, the best worst performance across all scenarios is located at the LTD case. In particular, the cumulative capacity costs do not exceed 2224.7 billion $€$, for any scenario's realisation. This is the risk-averse case decision-making. 
Table 1 Cumulative 2010-2050 investment capacity costs of the optimal portfolios across different scenarios (in billion $€(2010)$ )

\begin{tabular}{l|l|l|l|c}
\hline Portfolios/scenarios & Scenario OTR & Scenario OTD & Scenario LTR & Scenario LTD \\
\hline OTR-optimal & 1995.1 & 2507.3 & 9248.1 & $13,079.3$ \\
\hline OTD-optimal & 2065.0 & 2157.2 & 6678.4 & 7890.4 \\
\hline LTR-optimal & 2027.0 & 2448.6 & 2039.1 & 2641.8 \\
\hline LTD-optimal & 2097.3 & 2206.5 & 2112.9 & 2224.7 \\
\hline
\end{tabular}

Table 2 Regret values for the investment costs

\begin{tabular}{l|c|l|l|c}
\hline Portfolios/scenarios & Scenario OTR & Scenario OTD & Scenario LTR & Scenario LTD \\
\hline OTR-optimal & 0.0 & 350.1 & 7209.0 & $10,854.6$ \\
\hline OTD-optimal & 69.9 & 0.0 & 4639.3 & 5665.7 \\
\hline LTR-optimal & 31.9 & 291.4 & 0.0 & 417.1 \\
\hline LTD-optimal & 102.2 & 49.3 & 73.8 & 0.0 \\
\hline
\end{tabular}

Table 3 Cumulative 2010-2050 emissions (in GtCO2)

\begin{tabular}{l|l|l|l|l}
\hline Portfolios/scenarios & Scenario OTR & Scenario OTD & Scenario LTR & Scenario LTD \\
\hline OTR-optimal & 41.0 & 42.5 & 43.1 & 44.3 \\
\hline OTD-optimal & 28.2 & 28.2 & 31.0 & 31.4 \\
\hline LTR-optimal & 42.3 & 42.6 & 42.5 & 43.2 \\
\hline LTD-optimal & 30.6 & 29.7 & 30.4 & 29.9 \\
\hline
\end{tabular}

Table 4 Emissions regret values

\begin{tabular}{l|l|l|l|l}
\hline Portfolios/scenarios & Scenario OTR & Scenario OTD & Scenario LTR & Scenario LTD \\
\hline OTR-optimal & 12.8 & 14.3 & 12.7 & 14.4 \\
\hline OTD-optimal & 0.0 & 0.0 & 0.6 & 1.5 \\
\hline LTR-optimal & 14.1 & 14.4 & 12.1 & 13.3 \\
\hline LTD-optimal & 2.4 & 1.5 & 0.0 & 0.0 \\
\hline
\end{tabular}

To apply the min-max regret criterion, we need the regret values for the costs across all scenarios (Table 2). In this case, the two approaches coincide, i.e. the more robust strategy is still located at the LTD-optimal portfolio.

Regarding the second objective, that is, the cumulative emissions for the 2010-2050 period, these are presented in Table 3. The corresponding regret values in terms of emissions are presented in Table 4. The min-max strategy corresponds to the LTD case, bounding the total emissions at the level of $30.6 \mathrm{GtCO} 2$, independently of any scenario's realisation. On the contrary, min-max regret analysis points to the OTD strategy. This is the classical case between the risk-averse and the riskseeking decision maker. More precisely, the OTD portfolio contains better performances (28.2 GtCO2) from the LTD portfolio. On the other hand, based on the 
2010-2050 emmisions (GtCO2)

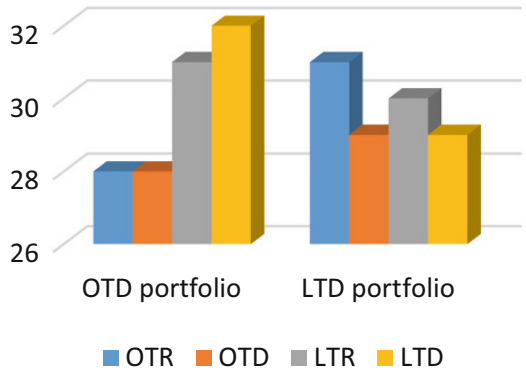

2010-2050 investment cost

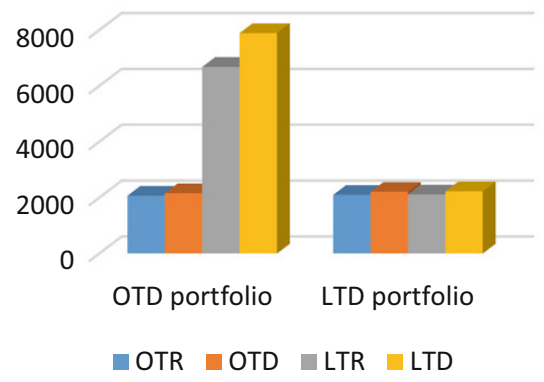

Fig. 4 Cumulative emissions and investment capacity costs of the optimal portfolios across different scenarios

Table 5 Relative joint objectives

\begin{tabular}{l|l|l|l|l}
\hline Portfolios/scenarios & Scenario OTR & Scenario OTD & Scenario LTR & Scenario LTD \\
\hline OTR-optimal & $(1.00,1.45)$ & $(1.16,1.49)$ & $(3.53,1.41)$ & $(5.87,1.48)$ \\
\hline OTD-optimal & $(1.03,1.00)$ & $(1.00,1.00)$ & $(2.27,1.01)$ & $(3.54,1.05)$ \\
\hline LTR-optimal & $(1.01,1.50)$ & $(1.13,1.51)$ & $(1.00,1.39)$ & $(1.18,1.44)$ \\
\hline LTD-optimal & $(1.05,1.08)$ & $(1.02,1.05)$ & $(1.03,1.00)$ & $(1.00,1.00)$ \\
\hline
\end{tabular}

min-max regret criterion, the LTD scenario results in higher emissions (29.9 $\mathrm{GtCO} 2$ ). A visual representation reflecting the robustness structure of the two different objectives (investment costs and emissions) is presented in Fig. 4.

If we consider simultaneously the two objective functions (costs and emissions), we notice that a conflict occurs. Following the min-max regret analysis, the costoriented robust strategy is located in LTD optimality, while in the emissions case, regret robustness corresponds to the OTD-optimal portfolio. Coping with this conflict, we apply the min-max regret criterion for the joint objective $E^{s}=\left(E_{1}^{s}, E_{2}^{s}\right)$, where $E_{1}^{s}$ and $E_{2}^{s}$ represent the cumulative costs and emissions, respectively, across scenarios $s \in\{$ OTR, OTD, LTR, LTD $\}$. First, we identify the optimal state per scenario, represented by $\left(E_{1 *}^{s}, E_{2 *}^{s}\right)$. Next, to avoid the curse of non-homogeneity, we consider the relative performance (RP) per scenario, with respect to the corresponding optimal situation, that is,

$$
R P(s):=\left(\frac{E_{1}^{s}}{E_{1 *}^{s}}, \frac{E_{2}^{s}}{E_{2 *}^{s}}\right), s \in\{\mathrm{OTR}, \mathrm{OTD}, \mathrm{LTR}, \mathrm{LTD}\} .
$$

Then, we obtain the relative joint performances in Table 5. Note that, in terms of relative performances, optimal situations correspond to the unit values. This means that, for each scenario, the optimal situation corresponds to $(1,1)$. To identify the more robust joint strategy, we will apply the min-max regret criterion for the relative joint objectives. In this case, since the elements belong to $\mathbb{R}_{+}^{2}$, we measure the deviation from optimality in terms of the Euclidean norm, that is, 
Table 6 Relative regret values

\begin{tabular}{l|l|l|l|l}
\hline Portfolios/scenarios & Scenario OTR & Scenario OTD & Scenario LTR & Scenario LTD \\
\hline OTR-optimal & 0.44 & 0.52 & 0.4 & 4.89 \\
\hline OTD-optimal & 0.03 & 0.00 & 1.27 & 2.54 \\
\hline LTR-optimal & 0.50 & 0.52 & 0.38 & 0.47 \\
\hline LTD-optimal & 0.09 & 0.05 & 0.03 & 0.00 \\
\hline
\end{tabular}

$$
\operatorname{dist}(x, y)=\left(\left(x_{1}-x_{2}\right)^{2}+\left(y_{1}-y_{2}\right)^{2}\right)^{1 / 2},
$$

for any $\left(x_{1}, y_{1}\right),\left(x_{2}, y_{2}\right) \in \mathbb{R}_{+}^{2}$. Then, the min-max regret criterion for the relative case is expressed as follows:

$$
\mathrm{MMR}=\arg \min _{P} \max _{s}(\operatorname{dist}(R P(s),(1,1))),
$$

where $P$ refers to the set of the four examined optimal investment portfolios. The regret values, in terms of the relative objective functions, are presented in Table 6. Applying the min-max regret criterion to the relative regret values, we conclude that the joint robust strategy is LTD, being in accordance with the distinguished application of the pure min-max criterion.

Based on the above analysis, we highlight the following observations:

- In the min-max setting, the LTD strategy is the optimal, expressing the desire of the conservative decision maker in any of the examined future development.

- With the min-max regret approach, the LTD strategy for cost and the OTD strategy for emissions create the least regret for the decision maker. If, however, joint relative regret analysis is applied to the future optimal development, then LTD strategy is established to be the robust one.

To provide some policy recommendations emerging from the above analysis, it is observed that:

- Portfolios for decarbonisation scenarios are more robust. This is due to the fact that nuclear remains in the mix until 2050, while the introduction of CCS technologies in the mix comes much earlier than in the reference scenario.

- In the optimised transmission portfolios, even though an important priority is considered, if the new generation built is based on this scenario and not realised in terms of infrastructure and investments, then the resulting regret could be enormous. From a technical point of view, this situation is realistic, considering, for example, that balancing issues will be far more challenging.

\section{Conclusions}

In this study, different emissions reduction technologies are considered for the identification of optimal policy mixes towards mitigating GHG emissions. Optimal electricity generation portfolios are determined through an EU electricity investment 
model, by considering different scenarios on transmission expansion and decarbonisation. Then, the performance of portfolios' long-term strategies is stress tested on the basis of investment costs and cumulative emissions. In this regard, we notice that technologies such as nuclear and CCS are found to be crucial, in the sense that forming portfolios with optimised transmission expansion proves to be inconsistent with the stress test analysis results. To this end, robustness tools such as the min-max regret criterion contributed to explore a posteriori more insight into the scenarios' assumptions, showing that combining modelling approaches provide a new dimension on assessing pathways of the energy transition.

Concluding, we found that decarbonisation scenarios are the preferred strategy for all cases. However, the limited decarbonisation strategy is the more robust, resulting in the least regret.

In this study, the limitations primarily involve the selection of the four scenarios; furthermore, future research may be directed to the investigation of the impact of additional objective functions to apply the min-max and the min-max regret criteria. Also, future research should consider analysing the evolution of CCS technologies and the respective risks of investing in CCS. The technology is still not commercially viable and perhaps does not become a reality. It is thus important to calculate the costs (regret), if pathways consider this development.

Acknowledgement The current paper was primarily based on the research conducted within the framework of the Horizon 2020 European Commission projects "Navigating the Roadmap for Clean, Secure and Efficient Energy Innovation (SET-Nav)" grant agreement No 691843 and "Transitions pathways and risk analysis for climate change mitigation and adaptation strategies (TRANSrisk)" grant agreement No. 642260. The content of the paper is the sole responsibility of its authors and does not necessary reflect the views of the European Commission.

\section{Appendices}

\section{Appendix 1 Nomenclature Used in the EMPIRE Model Formulation}

\begin{tabular}{l|l}
\hline Sets & \\
\hline $\mathcal{N}$ & Nodes (one per country) \\
\hline $\mathcal{G}$ & Generators. The set $\mathcal{G}_{n}$ is the set of all generators at node $n$ \\
\hline $\mathcal{L}$ & $\begin{array}{l}\text { Transmission lines (exchange corridors) between neighbouring nodes in the trans- } \\
\text { mission system }\end{array}$ \\
\hline $\mathcal{A}_{n}^{\text {in/out }}$ & $\begin{array}{l}\text { Arcs to/from neighbouring nodes in the transmission system. Note that for every } \\
\text { line connecting two nodes in the transmission system, there exist two arcs. These } \\
\text { are used to represent directional flow }\end{array}$ \\
\hline $\mathcal{H}$ & $\begin{array}{l}\text { Operational hours. The set } \mathcal{H}_{s} \text { is the set of all operational hours in season } s . \text { The } \mathcal{H}_{s}^{-} \\
\text {is the set of all operational hours except the first hour in season } s\end{array}$ \\
\hline $\mathcal{S}$ & $\begin{array}{l}\text { Seasons: } 1 \text { representative week per season and } 2 \text { weeks with extreme load and RES } \\
\text { situations }\end{array}$ \\
\hline$\Omega$ & Stochastic scenarios $\omega \in \Omega$ \\
\hline $\mathcal{T}$ & Aggregate generation technologies (e.g. coal, gas, wind, solar, etc.) \\
\hline
\end{tabular}




\begin{tabular}{|c|c|}
\hline \multicolumn{2}{|c|}{ Decision variables (all non-negative) } \\
\hline$x_{g i}^{\text {gen }}$ & Investment in capacity for generator $g$ in year $i$ \\
\hline$x_{l j}^{\operatorname{tran}}$ & Investment in capacity for transmission line $l$ in year $i$ \\
\hline$y_{\text {ghi } \omega}^{\text {gen }}$ & Production on generator $g$, operational hour $h$, year $i$, stochastic scenario $\omega$ \\
\hline$y_{\text {ahi } \omega}^{\text {flow }}$ & Flow on arc $a$, operational hour $h$, year $i$, stochastic scenario $\omega$ \\
\hline$y_{\text {nhi } \omega}^{\text {pump }}$ & $\begin{array}{l}\text { Energy used for pumping on pump } p \text {, operational hour } h \text {, year } i \text {, stochastic } \\
\text { scenario } \omega\end{array}$ \\
\hline$y_{\text {nhi } \omega}^{\mathrm{LL}}$ & Load shedding at node $n$, operational hour $h$, year $i$, stochastic scenario $\omega$ \\
\hline$w_{\text {nhi }}^{\text {upper }}$ & $\begin{array}{l}\text { Water-level upper reservoir for pump storage in node } n \text {, op. hour } h \text {, year } i \text {, } \\
\text { scenario } \omega\end{array}$ \\
\hline \multicolumn{2}{|l|}{ Parameters } \\
\hline$\delta_{i}$ & Discount factor year $i$ (at rate interest rate $r$, this is $\delta_{i}=(1+r)^{-5 i}$ ) \\
\hline$\alpha_{h}$ & $\begin{array}{l}\text { Operational hour scale factor. This factor represents the total number of hours in a } \\
\text { year represented by the operational hour } h \text {. Summing a variable/parameter scaled } \\
\text { by } \alpha_{h} \text { for all } h \in \mathcal{H} \text { yields a yearly total, e.g. } \sum_{h \in \mathcal{H}} \alpha_{h} \xi_{\text {nhi }}^{\text {load }} \text { is the total electric } \\
\text { energy consumption for node } n \text { in year } i \text {, scenario } \omega\end{array}$ \\
\hline$p_{\omega}$ & Probability of scenario $\omega$ for the stochastic parameters \\
\hline$c_{g i}^{\text {gen }}$ & $\begin{array}{l}\text { Total cost (fixed and capital costs) incurred by investing in } 1 \mathrm{MW} \text { new capacity for } \\
\text { generator } g\end{array}$ \\
\hline$c_{l i}^{\operatorname{tran}}$ & $\begin{array}{l}\text { Total cost (fixed and capital costs) incurred by investing in } 1 \mathrm{MW} \text { new exchange } \\
\text { capacity for line } l\end{array}$ \\
\hline$q_{g i}^{\text {gen }}$ & $\begin{array}{l}\text { Variable costs (fuel }+ \text { emission }+\mathrm{O} \& \mathrm{M} \text { ) incurred by producing } 1 \mathrm{MWh} \text { of electric } \\
\text { energy on generator } g \text { in year } i\end{array}$ \\
\hline$q_{n i}^{\mathrm{VoLL}}$ & Cost of using load-shedding variable $y_{\text {nhi } \omega}^{\mathrm{LL}}$ \\
\hline$\xi_{\text {nhi } \omega}^{\text {load }}$ & Load at node $n$ in operational hour $h$, year $i$ and stochastic scenario $\omega$ \\
\hline$\xi_{\text {ghi }}^{\text {gen }}$ & $\begin{array}{l}\text { Available share of generation capacity for generator } g \text { in operational hour } h \text {, year } i \text {, } \\
\text { stochastic scenario } \omega \text {. Note that for thermal generation technologies and regulated } \\
\text { hydropower the availability parameters are constant across all } \omega \in \Omega\end{array}$ \\
\hline$\xi_{\text {gsi }}^{\text {RegHydroLim }}$ & Total energy available for production in season $s$ \\
\hline$\rho_{g i}$ & Retired share of generator $g$ 's initial capacity by year $i$ \\
\hline$\gamma_{g}^{\text {gen }}$ & $\begin{array}{l}\text { Limit on total upward ramping as a fraction of total installed capacity for generator } \\
g\end{array}$ \\
\hline $\bar{x}_{g 0}^{\text {gen }}$ & Initial installed capacity generator $g$ \\
\hline $\bar{x}_{l 0}^{\operatorname{tran}}$ & Initial exchange capacity line $l$ \\
\hline $\bar{x}_{t n^{*}}^{\text {gen }}$ & $\begin{array}{l}\text { Upper bound on (period-wise/cumulative) investments in new capacity for gener- } \\
\text { ator } g\end{array}$ \\
\hline $\bar{x}_{l^{*}}^{\operatorname{tran}}$ & Upper bound on (period-wise) investments in new exchange capacity line $l$ \\
\hline$\eta_{a}^{\text {line }}$ & Exchange losses on arc $a$ (given as a share of the total flow) \\
\hline$\eta_{n}^{\text {pump }}$ & Pump efficiency for pump storage in node $n$ \\
\hline$h r_{g i}$ & Heat rate generator $g$, year $i$ \\
\hline$e_{f}$ & Carbon content fuel $f$ \\
\hline
\end{tabular}




\section{Appendix 2 Technological Assumptions for EMPIRE Implementation}

Table 7 Investment costs of generation technologies in EMPIRE

\begin{tabular}{l|r|r|r|r|r|r|r|l}
\hline Technology & 2020 & 2025 & 2030 & \multicolumn{1}{|c|}{2035} & 2040 & 2045 & 2050 & Unit \\
\hline Lignite & 1600 & 1600 & 1600 & 1600 & 1600 & 1600 & 1600 & $€_{2010} / \mathrm{kW}$ \\
\hline Lignite CCS adv & & 2600 & 2530 & 2470 & 2400 & 2330 & 2250 & $€_{2010} / \mathrm{kW}$ \\
\hline Coal & 1500 & 1500 & 1500 & 1500 & 1500 & 1500 & 1500 & $€_{2010} / \mathrm{kW}$ \\
\hline Coal CCS adv & & 2500 & 2430 & 2370 & 2300 & 2230 & 2150 & $€_{2010} / \mathrm{kW}$ \\
\hline Gas OCGT & 400 & 400 & 400 & 400 & 400 & 400 & 400 & $€_{2010} / \mathrm{kW}$ \\
\hline Gas CCGT & 800 & 800 & 800 & 800 & 800 & 800 & 800 & $€_{2010} / \mathrm{kW}$ \\
\hline Gas CCS adv & & 1350 & 1330 & 1310 & 1290 & 1270 & 1250 & $€_{2010} / \mathrm{kW}$ \\
\hline Bio & 2250 & 2250 & 2250 & 2250 & 2250 & 2250 & 2250 & $€_{2010} / \mathrm{kW}$ \\
\hline Nuclear & 4500 & 4500 & 4500 & 4500 & 4500 & 4500 & 4500 & $€_{2010} / \mathrm{kW}$ \\
\hline Hydro regulated & 3000 & 3000 & 3000 & 3000 & 3000 & 3000 & 3000 & $€_{2010} / \mathrm{kW}$ \\
\hline Hydro RoR & 4000 & 4000 & 4000 & 4000 & 4000 & 4000 & 4000 & $€_{2010} / \mathrm{kW}$ \\
\hline Wind onshore & 1033 & 1002 & 972 & 942 & 912 & 881 & 851 & $€_{2010} / \mathrm{kW}$ \\
\hline Wind offshore & 3205 & 2770 & 2510 & 2375 & 2290 & 2222 & 2172 & $€_{2010} / \mathrm{kW}$ \\
\hline Solar & 826 & 653 & 481 & 463 & 445 & 427 & 409 & $€_{2010} / \mathrm{kW}$ \\
\hline
\end{tabular}

Note: Data for fossil fuel technologies (incl. advanced CCS) come from ZEP (2013). Source of wind onshore and offshore (Gerbaulet and Lorenz 2017). Solar PV costs are based on the medium scenario in Fraunhofer ISE (2015)

Table 8 Efficiency of thermal power plants in EMPIRE

\begin{tabular}{l|l|l|l|l|l|l|l|l|l}
\hline Technology & 2015 & 2020 & 2025 & 2030 & 2035 & 2040 & 2045 & 2050 & Unit \\
\hline Lignite exist & 35 & 36 & 36 & 36 & 36 & 36 & 37 & 37 & $\%$ \\
\hline Lignite & 44 & 45 & 45 & 46 & 47 & 48 & 48 & 49 & $\%$ \\
\hline Lignite CCS adv & & & 37 & 39 & 40 & 41 & 42 & 43 & $\%$ \\
\hline Coal exist & 38 & 38 & 38 & 38 & 38 & 39 & 39 & 39 & $\%$ \\
\hline Coal & 46 & 46 & 47 & 47 & 48 & 48 & 49 & 49 & $\%$ \\
\hline Coal CCS adv & & & 39 & 40 & 41 & 41 & 42 & 43 & $\%$ \\
\hline Gas exist & 49 & 50 & 51 & 52 & 52 & 53 & 54 & 55 & $\%$ \\
\hline Gas OCGT & 40 & 41 & 41 & 41 & 41 & 42 & 42 & 42 & $\%$ \\
\hline Gas CCGT & 60 & 60 & 60 & 61 & 63 & 64 & 65 & 66 & $\%$ \\
\hline Gas CCS adv & & & 52 & 54 & 56 & 57 & 58 & 60 & $\%$ \\
\hline Oil exist & 38 & 38 & 38 & 38 & 38 & 38 & 38 & 38 & $\%$ \\
\hline Bio exist & 35 & 35 & 35 & 35 & 35 & 35 & 35 & 35 & $\%$ \\
\hline Bio & 36 & 36 & 37 & 38 & 38 & 39 & 39 & 40 & $\%$ \\
\hline Nuclear & 36 & 36 & 36 & 37 & 37 & 37 & 37 & 37 & $\%$ \\
\hline Source ZEP 2013$)$ & & & & & & & & &
\end{tabular}

Source: ZEP (2013) 
Table 9 Fixed operation and maintenance costs in EMPIRE

\begin{tabular}{|c|c|c|c|c|c|c|c|c|}
\hline & 2020 & 2025 & 2030 & 2035 & 2040 & 2045 & 2050 & Unit \\
\hline Lignite & 32.4 & 32.4 & 32.4 & 32.4 & 32.4 & 32.4 & 32.4 & $€_{2010} / \mathrm{kW} / \mathrm{an}$ \\
\hline Lignite CCS & & 51.4 & 50.0 & 48.7 & 47.4 & 46.1 & 44.7 & $€_{2010} / \mathrm{kW} / \mathrm{an}$ \\
\hline Coal & 31.1 & 31.1 & 31.1 & 31.1 & 31.1 & 31.1 & 31.1 & $€_{2010} / \mathrm{kW} / \mathrm{an}$ \\
\hline Coal CCS & & 47.0 & 45.9 & 44.7 & 43.6 & 42.5 & 41.4 & $€_{2010} / \mathrm{kW} / \mathrm{an}$ \\
\hline Gas OCGT & 19.5 & 19.5 & 19.5 & 19.5 & 19.5 & 19.5 & 19.5 & $€_{2010} / \mathrm{kW} / \mathrm{an}$ \\
\hline Gas CCGT & 30.4 & 30.4 & 30.4 & 30.4 & 30.4 & 30.4 & 30.4 & $€_{2010} / \mathrm{kW} / \mathrm{an}$ \\
\hline Gas CCS & & 46.9 & 46.9 & 46.9 & 46.9 & 46.9 & 46.9 & $€_{2010} / \mathrm{kW} / \mathrm{an}$ \\
\hline Nuclear & 127.0 & 123.3 & 119.5 & 115.8 & 112.1 & 108.3 & 104.6 & $€_{2010} / \mathrm{kW} / \mathrm{an}$ \\
\hline Wave & 153.8 & 153.8 & 153.8 & 153.8 & 153.8 & 153.8 & 153.8 & $€_{2010} / \mathrm{kW} / \mathrm{an}$ \\
\hline Geo & 92.3 & 92.3 & 92.3 & 92.3 & 92.3 & 92.3 & 92.3 & $€_{2010} / \mathrm{kW} / \mathrm{an}$ \\
\hline Hydro regulated & 125.0 & 125.0 & 125.0 & 125.0 & 125.0 & 125.0 & 125.0 & $€_{2010} / \mathrm{kW} / \mathrm{an}$ \\
\hline Hydro RoR & 125.0 & 125.0 & 125.0 & 125.0 & 125.0 & 125.0 & 125.0 & $€_{2010} / \mathrm{kW} / \mathrm{an}$ \\
\hline Bio & 46.3 & 45.3 & 44.3 & 43.3 & 42.3 & 41.3 & 40.3 & $€_{2010} / \mathrm{kW} / \mathrm{an}$ \\
\hline Wind onshore & 52.6 & 51.7 & 50.9 & 50.0 & 49.1 & 48.2 & 47.3 & $€_{2010} / \mathrm{kW} / \mathrm{an}$ \\
\hline Wind offshore & 127.6 & 122.4 & 117.2 & 112.0 & 106.8 & 101.6 & 96.4 & $€_{2010} / \mathrm{kW} / \mathrm{an}$ \\
\hline Solar & 18.6 & 17.1 & 15.7 & 14.3 & 12.9 & 11.4 & 10.0 & $€_{2010} / \mathrm{kW} / \mathrm{an}$ \\
\hline
\end{tabular}

Source: ZEP (2013). Solar PV costs from Fraunhofer ISE (2015)

Table 10 Variable operation and maintenance costs in EMPIRE

\begin{tabular}{l|l|l|l|l|l|l|l|l}
\hline & 2020 & 2025 & 2030 & 2035 & 2040 & 2045 & 2050 & Unit \\
\hline Lignite & 0.5 & 0.5 & 0.5 & 0.5 & 0.5 & 0.5 & 0.5 & $€ 2010 / \mathrm{MWh}$ \\
\hline Lignite CCS & 0.0 & 3.3 & 3.3 & 3.3 & 3.3 & 3.3 & 3.3 & $€ 2010 / \mathrm{MWh}$ \\
\hline Coal & 0.5 & 0.5 & 0.5 & 0.5 & 0.5 & 0.5 & 0.5 & $€ 2010 / \mathrm{MWh}$ \\
\hline Coal CCS & 0.0 & 2.5 & 2.5 & 2.5 & 2.5 & 2.5 & 2.5 & $€ 2010 / \mathrm{MWh}$ \\
\hline Gas OCGT & 0.5 & 0.5 & 0.5 & 0.5 & 0.5 & 0.5 & 0.5 & $€ 2010 / \mathrm{MWh}$ \\
\hline Gas CCGT & 0.5 & 0.5 & 0.5 & 0.5 & 0.5 & 0.5 & 0.5 & $€ 2010 / \mathrm{MWh}$ \\
\hline Gas CCS & 0.0 & 1.9 & 1.9 & 1.9 & 1.9 & 1.9 & 1.9 & $€ 2010 / \mathrm{MWh}$ \\
\hline Nuclear & 1.7 & 1.7 & 1.6 & 1.6 & 1.5 & 1.5 & 1.4 & $€ 2010 / \mathrm{MWh}$ \\
\hline
\end{tabular}

Source: ZEP (2013). Variable costs and operation and maintenance costs of other technologies assumed to be included in the fixed operation and maintenance costs. For CCS technologies there is an additional cost component of $20 €_{2010} / \mathrm{tCO}_{2}$ stored to account for transport and storage costs (this cost is flat for all years)

Table 11 Investment costs of storage technologies in EMPIRE

\begin{tabular}{|c|c|c|c|c|c|c|c|c|}
\hline Technology & 2020 & 2025 & 2030 & 2035 & 2040 & 2045 & 2050 & Unit \\
\hline Pump storage (power) & 1000 & 1000 & 1000 & 1000 & 1000 & 1000 & 1000 & $€_{2010} / \mathrm{kW}$ \\
\hline Pump storage (energy) & 100 & 100 & 100 & 100 & 100 & 100 & 100 & $€_{2010} / \mathrm{kWh}$ \\
\hline Li-ion utility battery & 246 & 198 & 198 & 198 & 198 & 198 & 198 & $€_{2010} / \mathrm{kWh}$ \\
\hline
\end{tabular}

Source: Pump-storage costs are based on own assumption. Lithium-ion battery costs are based on an adapted version of the medium cost scenario in Cole et al. (2016). For pump storage the power and energy capacity investments are decoupled. $\mathrm{Li}$-ion batteries are assumed to be $0.5 \mathrm{C}$ (i.e. capable to discharge from full to empty in $2 \mathrm{~h}$ ) 
Table 12 Investment costs of interconnectors in EMPIRE

\begin{tabular}{l|r|r|r|r|r|r|r|l}
\hline & 2020 & 2025 & 2030 & 2035 & 2040 & 2045 & 2050 & Unit \\
\hline HV lines & 662 & 662 & 604 & 604 & 604 & 604 & 604 & $€ 2010 / \mathrm{MW} / \mathrm{km}$ \\
\hline HV cables & 2769 & 2769 & 2160 & 2160 & 1551 & 1551 & 1551 & $€ 2010 / \mathrm{MW} / \mathrm{km}$ \\
\hline
\end{tabular}

Table 13 Total European-installed power generation capacity in 2015 in EMPIRE by technology

\begin{tabular}{l|l|l|l|l|l|l|l|l|l|l}
\hline Lignite & Coal & CCGT & Oil & Bio & Nuclear & Hydro & Wind & Solar PV & Other & Unit \\
\hline 60 & 108 & 232 & 26 & 25 & 125 & 158 & 142 & 95 & 1 & GWp \\
\hline
\end{tabular}

Sources: Solar potentials from Gils et al. (2017). Wind potentials from IEA (2016). Nuclear maximum capacities based on visions 1 and 2 presented in ENTSO-E (2015). Hydro capacities are own assumptions

\section{References}

Awerbuch, S., \& Berger, M. (2003). Applying portfolio theory to EU electricity planning and policy-making, IEA/EET Working Paper, Report Number EET/2003/03, Paris.

Bauer, N., Calvin, K., Emmerling, J., Fricko, O., Fujimori, S., Hilaire, J., \& de Boer, H. S. (2017). Shared socio-economic pathways of the energy sector-quantifying the narratives. Global Environmental Change, 42, 316-330.

Chang, N. B., \& Davila, E. (2007). Minimax regret optimization analysis for a regional solid waste management system. Waste Management, 27, 820-832.

Cole, W. J., Marcy, C., Krishnan, V. K., \& Margolis, R. (2016). Utility-scale lithium-ion storage cost projections for use in capacity expansion models. 2016 North American Power Symposium (NAPS), pp. 1-6.

Crespo del Granado, P., van Nieuwkoop, R. H., Kardakos, E. G., \& Schaffner, C. (2018). Modelling the energy transition: A nexus of energy system and economic models. Energy Strategy Reviews, 20, 229-235.

Dong, C., Huang, G. H., Cai, Y. P., \& Xu, Y. (2011). An interval-parameter minimax regret programming approach for power management systems planning under uncertainty. Applied Energy, 88, 2835-2845.

ENTSO-E. (2015). TYNDP 2016 Scenario Development Report - Final after public consultation, Brussels. https://www.entsoe.eu/Documents/TYNDP documents/TYNDP 2016/rgips/ TYNDP2016 market modelling data.xlsx

European Commission. (2011). Energy Roadmap 2050, COM(2011) 885/2. https://ec.europa.eu/ energy/en/topics/energy-strategy-and-energy-union/2050-energy-strategy

Fan, L., Hobbs, B. F., \& Norman, C. S. (2010). Risk aversion and $\mathrm{CO}_{2}$ regulatory uncertainty in power generation investment: Policy and modeling implications. Journal of Environmental Economics and Management, 60(3), 193-208.

Fraunhofer ISE. (2015). Current and future cost of photovoltaics. Long-term scenarios for market development, system prices and LCOE of utility-scale PV systems. Freiburg: Study on behalf of Agora Energiewende

Fuss, S., Szolgayová, J., Khabarov, N., \& Obersteiner, M. (2012). Renewables and climate change mitigation: Irreversible energy investment under uncertainty and portfolio effects. Energy Policy, 40, 59-68.

Gerbaulet, C., \& Lorenz, C. (2017). dynELMOD: A dynamic investment and dispatch model for the future European electricity market. DIW Data Documentation.

Gils, H. C., Scholz, Y., Pregger, T., Tena, D. L., \& Heide, D. (2017). Integrated modelling of variable renewable energy-based power supply in Europe. Energy, 127, 173-188. 
Haller, M., Ludig, S., \& Bauer, N. (2012). Decarbonization scenarios for the EU and MENA power system: Considering spatial distribution and short term dynamics of renewable generation. Energy Policy, 47, 282-290.

IEA. (2016). Nordic energy technology perspectives 2016. Paris: OECD.

IPCC. (2014). Climate Change 2014: Synthesis Report. In Core Writing Team, R. K. Pachauri \& L. A. Meyer (Eds.), Contribution of Working Groups I, II and III to the Fifth Assessment Report of the Intergovernmental Panel on Climate Change (151p.). Geneva, Switzerland: IPCC.

Jägemann, C., Fürsch, M., Hagspiel, S., \& Nagl, S. (2013). Decarbonizing Europe's power sector by 2050 - Analyzing the economic implications of alternative decarbonization pathways. Energy Economics, 40, 622-636.

Kaut, M., Midthun, K. T., Werner, A. S., Tomasgard, A., Hellemo, L., \& Fodstad, M. (2014). Multihorizon stochastic programming. Computational Management Science, 11(1-2), 179-193.

Kazakci, A. O., Rozakis, S., \& Vanderpooten, D. (2007). Energy supply in France: A min-max regret approach. Journal of the Operational Research Society, 106, 1470-1479.

Kouvelis, P., \& Yu, G. (1997). Robust discrete optimization and its applications, Nonconcex optimization and its applications (Vol. 14). Dordrecht: Kluwer Academic.

Li, Y. P., \& Huang, G. H. (2006). Minimax regret analysis for municipal solid waste management: An interval-stochastic programming approach. Journal of the Air \& Waste Management Association, 56(7), 931-944.

Li, Y. P., Huang, G. H., \& Chen, X. (2011). An interval-valued minimax-regret analysis approach for the identification of optimal greenhouse-gas abatement strategies under uncertainty. Energy Policy, 39, 4313-4324.

Li, S., Coit, D. W., \& Felder, F. (2016). Stochastic optimization for electric power generation expansion planning with discrete climate change scenarios. Electric Power Systems Research, $140,401-412$.

Loulou, R., \& Kanudia, A. (1999). Minimax regret strategies for greenhouse gas abatement: Methodology and application. Operations Research Letters, 25, 219-230.

McLoughlin, E., \& Bazilian M. (2006). Application of portfolio analysis to the Irish electricity generating mix in 2020, Sustainable Energy Ireland Working Paper.

Morris, J., Srikrishnan, V., Webster, M., \& Reilly, J. (2018). Hedging uncertainties: Electricity investment decisions under policy uncertainty. The Energy Journal, 39(1), 101-122.

Munoz, F. D., Hobbs, B. F., Ho, J. L., \& Kasina, S. (2014). An engineering-economic approach to transmission planning under market and regulatory uncertainties: WECC case study. IEEE Transactions on Power Systems, 29(1), 307-317.

Munoz, F. D., van der Weijde, A. H., Hobbs, B. F., \& Watson, J. P. (2017). Does risk aversion affect transmission and generation planning? A Western North America case study. Energy Economics, 64, 213-225.

National Technical University of Athens. (2010). The PRIMES energy systems model. Technical report. http://www.e3mlab.ntua.gr/manuals/PRIMsd.pdfS

Nikas, A., Doukas, H., Lieu, J., Alvarez Tinoco, R., Charisopoulos, V., Charisopoulos, V., \& van der Gaast, W. (2017). Managing stakeholder knowledge for the evaluation of innovation systems in the face of climate change. Journal of Knowledge Management, 21(5), 1013-1034.

Papapostolou, A., Karakosta, C., Nikas, A., \& Psarras, J. (2017). Exploring opportunities and risks for RES-E deployment under cooperation mechanisms between EU and Western Balkans: A multi-criteria assessment. Renewable and Sustainable Energy Reviews, 80, 519-530.

Raupach, M. R., Marland, G., Ciais, P., Quéré, C. L., Canadell, J. G., Klepper, G., et al. (2007). Global and regional drivers of accelerating $\mathrm{CO}_{2}$ emissions. Proceedings of the National Academy of Sciences Of the USA, 104, 10288-10293.

Richter, J. (2011). DIMENSION - A dispatch and investment model for European electricity markets. EWI Working Paper No. 11/03.

Seljom, P., \& Tomasgard, A. (2015). Short-term uncertainty in long-term energy system models A case study of wind power in Denmark. Energy Economics, 49, 157-167. 
Skar, C., Doorman, G. L., \& Tomasgard, A. (2014). The future European power system under a climate policy regime. In IEEE International Energy Conference, EnergyCon (pp. 337-344).

Skar, C., Doorman, G., Pérez-Valdés, G. A., Tomasgard, A. (2016a). A multi-horizon stochastic programming model for the European power system, CenSES Working Paper 2/2016.

Skar, C., Egging, R., \& Tomasgard, A. (2016b). The role of transmission and energy storage for integrating large shares of renewables in Europe. IAEE Energy Forum, Q1, 35-36.

Swider, D. J., \& Weber, C. (2007). The costs of wind's intermittency in Germany: Application of a stochastic electricity market model. European Transactions on Electrical Power, 17(2), 151-172.

Van der Weijde, A. H., \& Hobbs, B. F. (2012). The economics of planning electricity transmission to accommodate renewables: Using two-stage optimization to evaluate flexibility and the cost of disregarding uncertainty. Energy Economics, 34(6), 2089-2101.

White, B. (2007). A mean-variance portfolio optimization of California's generation mix to 2020, Report no. CEC-300-2007-009-D, California Energy Commission.

ZEP. (2013). $\mathrm{CO}_{2}$ capture and storage (CCS): Recommendations for transitional measures to drive deployment in Europe. Report by the European Technology Platform for Zero Emission Fossil Fuel Power Plants, Brussels.

ZEP. (2014). CCS and the electricity market: Modelling the lowest-cost route to decarbonising European power. Report by the European Technology Platform for Zero Emission Fossil Fuel Power Plants, Brussels.

Zhu, L., \& Fan, Y. (2010). Optimization of China's generating portfolio and policy implications based on portfolio theory. Energy, 35, 1391-1402.

Open Access This chapter is licensed under the terms of the Creative Commons Attribution 4.0 International License (http://creativecommons.org/licenses/by/4.0/), which permits use, sharing, adaptation, distribution and reproduction in any medium or format, as long as you give appropriate credit to the original author(s) and the source, provide a link to the Creative Commons license and indicate if changes were made.

The images or other third party material in this chapter are included in the chapter's Creative Commons license, unless indicated otherwise in a credit line to the material. If material is not included in the chapter's Creative Commons license and your intended use is not permitted by statutory regulation or exceeds the permitted use, you will need to obtain permission directly from the copyright holder.

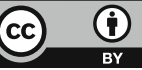

